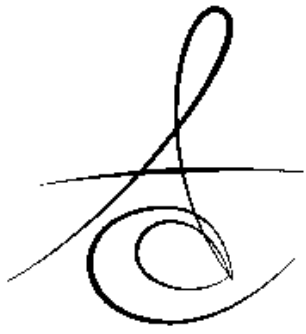

\title{
FARKLI KENAR BİTİM VE ALT YAPI DİZAYNLARININ ÇEŞİTLI ZİRKONYUM ALT YAPILAR ÜZERİNDEKİ VENER PORSELENİN KIRILMA DİRENCİNE ETKİSINIIN İNCELENMESİ ${ }^{*}$
}

EFFECT OF DIFFERENT MARGINAL FINISH LINES AND COPING DESIGNS ON THE FRACTURE RESISTANCE OF VENEERING PORCELAIN ON VARIOUS ZIRCONIA FRAMEWORKS ${ }^{*}$

\author{
Dr. Öğr. Üyesi Murat ALKURT*
}

Prof. Dr. Zeynep YEŞİL DUYMUŞ**

Makale Kodu/Article code: 3583

Makale Gönderilme tarihi: 19.02 .2018

Kabul Tarihi: 27.07 .2018

\section{öz}

Amaç: Bu çalışmada, kenar bitim ve alt yapı şekillerinin çeşitli zirkonyum alt yapılar üzerindeki vener porselenlerinin kırılma direncine etkisi in vitro olarak incelenmiştir.

Gereç ve Yöntem: Örneklerin elde edileceği kesilmiş üst 1. küçük azı dişini temsil eden güdükler; 1 . Güdük; 6 $\mathrm{mm}$ kuron boyu ve $6^{0}$ taper açısında $1 \mathrm{~mm}$ shoulder basamak ile anatomik oklüzal yüzeyli, 2. Güdük; $6 \mathrm{~mm}$ kuron boyu ve $6^{0}$ taper açısında $1 \mathrm{~mm}$ chamfer basamak ile anatomik oklüzal yüzeyli, 3. Güdük; $6 \mathrm{~mm}$ kuron boyu ve $6^{0}$ taper açısında, $1 \mathrm{~mm}$ shoulder basamak ile düz oklüzal yüzeyli, 4. Güdük; $6 \mathrm{~mm}$ kuron boyu ve $6^{0}$ taper açısında $1 \mathrm{~mm}$ chamfer basamak ile düz oklüzal yüzeyli olarak standardizasyonun sağlanması amacıyla CNC torna tezgahında hazırlanmıştır. Güdüklerden alınan ölçülerden 60 adet epoksi rezin güdük elde edilmiştir. Zirkonyum alt yapılar farklı yöntemlerle hazırlandıktan sonra üst yapı porseleni uygulanarak kuronlar tamamlanmıştır. Kuronlar epoksi rezin güdükler üzerine simante edildikten sonra vener porselenlerinin kırılma dirençleri Universal test cihazında saptanmıştır.

Bulgular: Veriler üç yönlü varyans analizi (ANOVA) ile değerlendirilmiştir. Kenar bitim şekli, alt yapı şekli ve materyallerin, materyaller ile alt yapı şekli, materyaller ile kenar bitim şekli arasındaki etkileşimin anlamlı olduğu, kenar bitim şekli ile alt yapı şekli, materyaller ile alt yapı şekli ve kenar bitim şekli arasındaki etkileşimlerin ise anlamlı olmadığı istatistiksel olarak tespit edilmiştir.

Sonuç: En yüksek vener porselen kırılma direnci değerlerinin alt yapısı anatomik şekilde hazırlanan chamfer basamaklı White Peaks kuronlarda, en düşük kırılma direnci değerlerinin ise alt yapısı düz şekilde hazırlanan chamfer basamaklı Lava kuronlarda olduğu görülmüştür.

Anahtar Kelimeler: Alt yapı şekli, kenar bitim şekli, kırılma direnci, zirkonyum alt yapılar

\begin{abstract}
Aim: In this in vitro study, the effect of finish line and coping design on the fracture resistance of veneer porcelains on the zirconia frameworks prepared through various methods was analyzed.
\end{abstract}

Material and Methods: To standardization, the dies representing the upper first premolar tooth were prepared in the CNC turning machine as: the first die; with a $6 \mathrm{~mm}$ crown length and at $6^{\circ}$ taper angle, having an anatomic occlusal surface with a $1 \mathrm{~mm}$ shoulder line, the second die; with a $6 \mathrm{~mm}$ crown length and at $6^{0}$ taper angle, having an anatomic occlusal surface with a $1 \mathrm{~mm}$ chamfer line, the third die; with a $6 \mathrm{~mm}$ crown length and at $6^{\circ}$ taper angle, having a flat occlusal surface with a 1 $\mathrm{mm}$ shoulder line, and the fourth die; with a $6 \mathrm{~mm}$ crown length and at $6^{\circ}$ taper angle, having a $1 \mathrm{~mm}$ chamfer line with a flat occlusal surface. 60 pieces of epoxy resin dies were obtained from the measurements taken from the dies. Zirconia frameworks had been prepared through different methods, then crowns were completed by applying the body porcelain. After cementation the crowns on the epoxy resin dies, the fracture resistance of veneer porcelains was measured by the Universal Test device.

Results: The data were analyzed by three-way variance analysis (ANOVA). It was statistically determined that the interaction between the finish line, coping design and materials; and the materials and coping design, and the finish line and the materials. However; no significant interaction was observed between the finish line and coping design; and the materials, coping design and the finish line.

Conclusion: The highest fracture resistance values of veneer porcelain was seen in chamfer line White Peaks crowns prepared anatomically, whereas the framework of the lowest fracture resistance values was seen in the chamfer line Lava crowns.

Key Words: Coping design, finish lines, fracture resistance, zirconia frameworks.

\footnotetext{
*Recep Tayyip Erdoğan Üniversitesi Diş Hekimliği Fakültesi Protetik Diş Tedavisi AD, Rize.

** Atatürk Üniversitesi Diş Hekimliği Fakültesi Protetik Diş Tedavisi AD, Erzurum.

${ }^{\text {}}$ Bu çalışma 2012/381 BAP proje numarası ile Atatürk Üniversitesi Bilimsel Araştırma Projeleri tarafından desteklenmistir.
} 


\section{GİRIŞ}

Günümüzde estetik ve biyouyumluluk açısından mükemmel özellik gösteren metal içermeyen protetik restorasyonların kullanımı hızla yaygınlaşmaktadır. ${ }^{1}$ Yttrium oksit ile stabilize edilen zirkonyum esaslı tam seramik restorasyonlar, arzu edilen estetiği sağlamaları ve yüksek kırılma dirençleri ile posterior bölgede uygulanan çok üyeli köprülerin yapımında metal alaşımlarına alternatif duruma gelmişlerdir. ${ }^{2}$

Vener porselenindeki koheziv kırıklar sonucu vener porseleninin alt yapıdan ayrılması, zirkonyum alt yapılı restorasyonlarda en sık karşılaşılan klinik başarısızlıklardandır. ${ }^{1}$ Seramik doğal yapısından dolayı kırılgan, düşük gerilme dayanıklılığına ve kırılma tokluğuna sahiptirler. ${ }^{3}$ Porselen yapısında görülen kırıkların önlemek amacıyla tam seramik restorasyonlarda birçok yöntem geliştirilmiştir. ${ }^{4} \mathrm{Bu}$ amaçla yapılan zirkonyum alt yapıların farklı şekillerde tasarlanması vener porselenlerinin kırılma dirençlerini arttırmıştır. ${ }^{5,6}$

Bu çalışma, çeşitli zirkonyum alt yapılar üzerindeki vener porselenlerinin kırıma direncine farklı kenar bitim ve alt yapı şekillerinin (anatomik ve anatomik olmayan) etkisini incelemek amacıyla yapılmıştır. Çalışmanın hipotezi, kenar bitim ve alt yapı şekillerinin vener porselenlerinin kırılma direncini değiştireceği yönündedir.

\section{MATERYAL VE METOD}

\section{Örneklerin Hazırlanması}

Örneklerin elde edileceği kesilmiş üst 1. küçük azı dişini temsil eden güdükler, standardizasyonun sağlanması amacıyla CNC torna tezgahında (Space Turn LB2000, Okuma Corp, Japonya) aşağıda belirtildiği şekilde hazırlanmıştır:

1. Güdük; $6 \mathrm{~mm}$ kuron boyu ve $6^{0}$ taper açısında $1 \mathrm{~mm}$ shoulder basamak ile anatomik oklüzal yüzeyli,

2. Güdük; $6 \mathrm{~mm}$ kuron boyu ve $6^{0}$ taper açısında $1 \mathrm{~mm}$ chamfer basamak ile anatomik oklüzal yüzeyli,

3. Güdük; $6 \mathrm{~mm}$ kuron boyu ve $6^{0}$ taper açısında, $1 \mathrm{~mm}$ shoulder basamak ile düz oklüzal (anatomik olmayan) yüzeyli,

4. Güdük; $6 \mathrm{~mm}$ kuron boyu ve $6^{0}$ taper açısında $1 \mathrm{~mm}$ chamfer basamak ile düz oklüzal (anatomik olmayan) yüzeyli olarak hazırlanmıştır (Şekil 1-4).
Hazırlanan güdüklerden silikon esaslı ölçü maddesi (Speedex, Coltène/Whaledent AG, Langenau, Almanya) kullanılarak çift karıştırma tekniği ile alınan ölçülerden 30 adet anatomik (15 adet shoulder ve 15 adet chamfer bitim hatlı) 30 adette anatomik olmayan (15 adet shoulder ve 15 adet chamfer bitim hatlı) epoksi rezin güdüklü model elde edilmiştir. Daha sonra alt yapıların hazırlanma işlemine geçilmiştir (Şekil 5).

Kullanılan alt yapı materyalleri ve hazırlama yöntemleri Tablo 1.'de gösterilmiştir.

Tablo 1. Çalışmada Kullanılan Materyaller

\begin{tabular}{|c|c|c|c|c|}
\hline Materyal & Yöntem & Blok & $\begin{array}{l}\text { Üretici } \\
\text { Firma }\end{array}$ & $\begin{array}{l}\text { Sinterizas- } \\
\text { yon }\end{array}$ \\
\hline Zirkonzahn & $\begin{array}{l}\text { Manuel } \\
\text { Dizayn } \\
\text { Manuel } \\
\text { Üretim } \\
\text { Pantografi }\end{array}$ & $\begin{array}{l}\text { 3Y-TZP } \\
\text { Blok } \\
\text { (Yeşil } \\
\text { Aşama) }\end{array}$ & $\begin{array}{l}\text { Stegger, } \\
\text { Gais, } \\
\text { Italya }\end{array}$ & $\begin{array}{l}1500^{\circ} \mathrm{C}^{\prime} \mathrm{de} 8 \\
\text { saat }\end{array}$ \\
\hline Lava & $\begin{array}{l}\text { CAD-CAM } \\
\text { Sistem }\end{array}$ & $\begin{array}{l}\text { 3Y-TZP } \\
\text { Blok } \\
\text { (Presinte } \\
\text { rize) }\end{array}$ & $\begin{array}{l}\text { 3M ESPE } \\
\text { Dental } \\
\text { AG, } \\
\text { Seefeld, } \\
\text { Almanya }\end{array}$ & $\begin{array}{l}\text { Ön kurutma } \\
\text { oda } \\
\text { sıcaklığında } \\
3.5 \text { saat, } \\
2.5 \text { saatte } \\
1500^{\circ} C^{\prime} \text { ye } \\
\text { çıarılıp, } \\
2 \text { saat } \\
1500^{\circ} C^{\prime} \text { de } \\
\text { bekletme }\end{array}$ \\
\hline $\begin{array}{l}\text { White } \\
\text { Peaks } \\
\text { (Copran } \\
\text { Zr) }\end{array}$ & $\begin{array}{l}\text { CAD-CAM } \\
\text { Sistem }\end{array}$ & $\begin{array}{l}\text { 3Y-TZP } \\
\text { Blok } \\
\text { (Tam } \\
\text { Sinterize) }\end{array}$ & $\begin{array}{l}\text { White } \\
\text { Peaks } \\
\text { Dental } \\
\text { Systems, } \\
\text { Essen, } \\
\text { Germany }\end{array}$ & $\begin{array}{l}\text { Bloklar tam } \\
\text { sinterize } \\
\text { olduğundan } \\
\text { sinterleme } \\
\text { işlemi } \\
\text { uygulanmamış } \\
\text { tır. }\end{array}$ \\
\hline
\end{tabular}

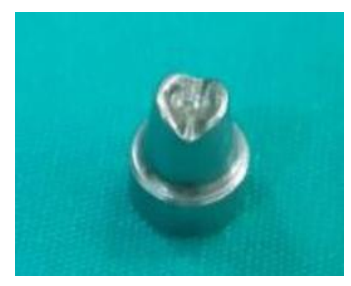

Şekil 1. Shoulder Bitim Hatı Anatomik Oklüzal Yüzeyli Güdük

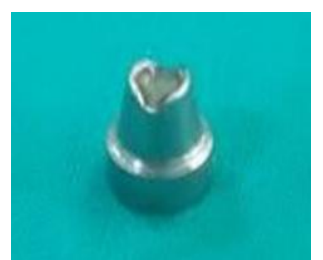

Şekil 2. Chamfer Bitim Hatlı Anatomik Oklüzal Yüzeyli Güdük

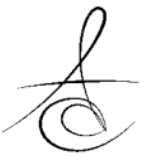




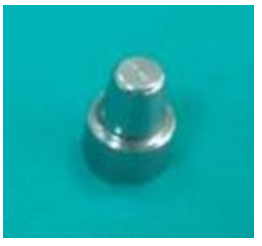

Şekil 3. Shoulder Bitim Hatlı Düz Oklüzal (Anatomik Olmayan) Yüzeyli Güdük

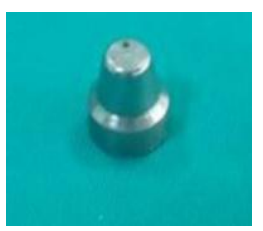

Şekil 4. Chamfer Bitim Hatlı Düz Oklüzal (Anatomik Olmayan) Yüzeyli Güdük
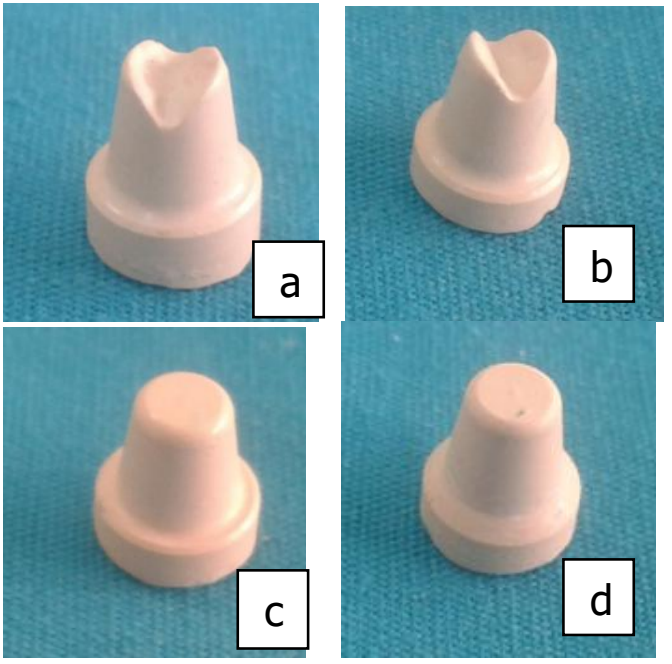

Şekil 5. Epoksi Rezin Güdükler; a) Shoulder Bitim Hatı Anatomik, b) Chamfer Bitim Hatlı Anatomik, c) Shoulder Bitim Hatlı Anatomik Olmayan, d) Chamfer Bitim Hatlı Anatomik Olmayan

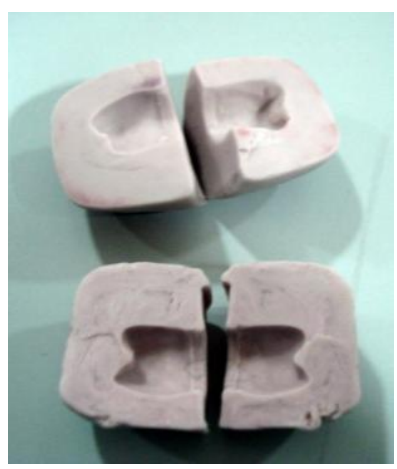

Şekil 6. Silikon İndeks Kalıplar

\section{Zirkonzahn Örneklerin Hazırlanması}

Kopya-freze esasına dayanan bu sistemde standardizasyonun sağlanabilmesi amacıyla anatomik ve düz oklüzal yüzeyli alt yapıların ön şekli CAD-CAM sistemi ile rezin esaslı materyalden hazırlanmıştır. Rezin maketler Zirkonzahn manuel freze ünitesine (Zirkograph O25 ECO, Zirkonzahn GmbH, Gais, İtalya) sabitlendikten sonra Zirkonzahn bloklardan alt yapıların üretim işlemine geçilmiştir. Freze işlemlerinin bitirilmesinden sonra sinterizasyon firınına (Zirkonofen 600/V2, Zirkonzahn GmbH, Gais, İtalya) konulmuştur.

\section{Lava Örneklerin Hazırlanması}

Hazırlanan modeller optik tarayıcı (LavaScanST, 3M ESPE Dental AG, Seefeld, Almanya) yardımı ile taranarak bilgisayar ortamına aktarımıştır. Sinterleme büzülmesini kompanse etmek amacıyla $\% 20$ geniş hazırlanan anatomik ve düz oklüzal yüzeyli alt yapıların dizayn işlemi Lava Dizayn (Lava Desing-LD, 3M ESPE Dental AG, Seefeld, Almanya) programı ile gerçekleştirilmiştir. Dizayn işlemi tamamlanan alt yapılar, Lava bloklardan (Lava Zirkonya, 3M ESPE Dental AG, Seefeld, Almanya) freze ünitesinde (LavaForm, 3M ESPE Dental AG, Seefeld, Almanya) şekillendirilmiştir. Daha sonra sinterizasyon firınına (LavaTerm, 3M ESPE Dental AG, Seefeld, Almanya) yerleştirilmiştir.

\section{Hazırlanması}

White Peaks (Copran Zr) Örneklerin

Tarayıcı ünitenin yalnızca beyaz rengi görebilmesinden dolayı, hazırlanan güdüklü modellerin bütün yüzeyleri day spreyle kaplanmışır. Daha sonra güdükler lazer tarayıcl (Roland LPX-60 3D Laser Scanner, Rolang Dg Corporation, Japonya) yardımı ile taranarak veriler bilgisayar ortamına aktarılmışıtı. Elde edilen veriler doğrultusunda sistemin kendine özgü olan yazilım (Roland Pixform Pro II, Rolang Dg Corporation, Japonya) programı kullanılarak iki farklı kenar bitim şeklinde anatomik ve düz oklüzal yüzeyli alt yapı dizaynları yapılmışır. Yazııı üzerinde oluşturulan veriler freze ünitesine (Roland DWX-50, Rolang Dg Corporation, Japonya) aktarılarak alt yapıların tam sinterize 3Y-TZP bloklardan (White Peaks Dental Systems, Essen, Almanya) üretimine başlanmıştır. Freze işlemi yaklaşık üç saat sürmüştür.

\section{Alt Yapılara Porselen Uygulanması}

Tüm alt yapılar kumpas ile kalınlıklar ölçülmüş, $0.5 \mathrm{~mm}$ olmayan örnekler yeniden hazırlanmışıı.

Standardizasyonun sağlanabilmesi için anatomik ve düz oklüzal yüzeyli (shoulder ve chamfer bitim

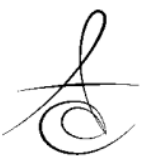


hatlı) birer alt yapı üzerine üst 1 . küçük azı dişinin anatomik özelliklerini yansıtan akrilikten kuron hazırlanmış, hazırlanan alt yapı-akrilik restorasyonların silikon esaslı ölçü maddesi ile ölçüleri alınmıştır. Porselen yapımında indeks olarak kullanabilmek amacıyla elde edilen ölçü, bistürü ile bukko-lingual yönde ortadan ikiye ayrımıştır (Şekil 6). Zirkonyum alt yapılara silikon indeks yardımıyla dentin porseleni (Vita VM9 VM Zahnfabrik, Bad Säckingen, Almanya) uygulanmış ve glaze işlemi gerçekleştirilmiştir.

Alt yapılara vener porseleni uygulandıktan sonra, örnekler rezin siman ile (Panavia F 2.0, Kuraray Dental, Japonya) ile üreticinin önerdiği şekilde epoksi rezin güdüklere simante edilmiştir.

\section{Kırılma Direnci Testi ve Kopma Şekli İncelenmesi}

Kırılma testi Instron Universal (Instron Corp, USA) test cihazı kullanılarak gerçekleştirilmiştir. Kuvvet uygulaması sırasında dik açıda hareketsiz kalması için örnekler, Instron aletinin alt parçasına yerleştirilen düzenek ile sabitlenmiştir. Cihazın hareketli olan üst parçasına ise ucunda $5 \mathrm{~mm}$ çapında çelik bilye bulunan bir kuvvet uygulayıcı uç yerleştirilmiştir. Örneklerin oklüzal yüzeylerinin tam orta noktasından ilk kırıma oluşuncaya kadar 0.5 mm/dakika başlık hızı ile kuvvet uygulanmıştır. Kırılma kuvvetleri Newton (N) cinsinden kaydedilmiştir. Elde edilen veriler, SPSS 16 programı kullanılarak üç yönlü varyans analizi ve Tukey HSD çoklu karşılaştırma testi kullanılarak istatistiksel olarak değerlendirilmiştir.

Tüm örneklerin kuvvet uygulama sonrasında kopma şekilleri, optik mikroskopta (Novex RZ-Range, Novex Inc., Amhem, Hollanda) incelenmiştir. Kopma şekilleri; vener porseleninin alt yapıdan tamamen ayrıldığı adeziv kopma, vener porseleninin tamamen kendi içinde kırıldığı koheziv kopma ve her iki kırılma tipinin de gözlendiği kombine kopma (adeziv + koheziv) olarak 3 gruba ayrılarak değerlendirilmiştir.

\section{BULGULAR}

\section{Kırılma Dirençlerinin Değerlendirilmesi}

Elde edilen verilerin değerlendirilmesi amacıyla 3-Yönlü varyans analizi kullanılmıştır. Varyans analiz tablosu incelendiğinde; alt yapı materyallerinin $(p<0.001)$, kenar bitim şekillerinin $(p=0.01)$, alt yapı şekillerinin $(p<0.001)$, alt yapı materyalleri ile alt yapı şekilleri $(p<0.001)$ arasındaki, alt yapı materyalleri ile kenar bitim şekilleri $(p<0.01)$ arasındaki etkileşimlerin anlamlı olduğu, kenar bitim şekilleri ile alt yapı şekilleri ( $p>0.05$ ) arasındaki alt yapı materyalleri, kenar bitim şekilleri ve alt yapı şekilleri arasındaki etkileşimlerin ise anlamlı ( $p>0.05$ ) olmadığı istatistiksel olarak tespit edilmiştir (Tablo 2).

Tablo 2. Varyans Analiz Tablosu

\begin{tabular}{|l|c|c|c|c|c|}
\hline $\begin{array}{l}\text { Varyasyon } \\
\text { Kaynakları }\end{array}$ & $\begin{array}{c}\text { Kareler } \\
\text { Toplamı }\end{array}$ & df & $\begin{array}{c}\text { Kareler } \\
\text { Ortalaması }\end{array}$ & $\mathrm{F}$ & Fark \\
\hline $\begin{array}{l}\text { Alt Yapı } \\
\text { Materyalleri }\end{array}$ & 5163150.033 & 2 & 2581575.017 & 292.826 & .000 \\
\hline $\begin{array}{l}\text { Kenar Bitim } \\
\text { Şekilleri }\end{array}$ & 63700.417 & 1 & 63700.417 & 7.225 & .010 \\
\hline Alt Yapı Şekilleri & 186038.017 & 1 & 186038.017 & 21.102 & .000 \\
\hline $\begin{array}{l}\text { Alt Yapı } \\
\text { Materyalleri*Alt } \\
\text { Yapı Şekilleri }\end{array}$ & 457005.433 & 2 & 228502.717 & 25.919 & .000 \\
\hline $\begin{array}{l}\text { Alt Yapı } \\
\text { Materyalleri*Kenar } \\
\text { Bitim Şekilleri }\end{array}$ & 95946.433 & 2 & 47973.217 & 5.442 & .007 \\
\hline $\begin{array}{l}\text { Kenar Bitim } \\
\text { Şekilleri*Alt Yapı } \\
\text { Şekilleri }\end{array}$ & 33559.350 & 1 & 33559.350 & 3.807 & .057 \\
\hline $\begin{array}{l}\text { Alt Yapı } \\
\text { Materyalleri*Kenar } \\
\text { Bitim Şekilleri*Alt } \\
\text { Yapı Şekilleri }\end{array}$ & 8724.100 & 2 & 4362.050 & .495 & .613 \\
\hline Hata & & & & & \\
\hline Toplam & $1.044 E 8$ & 60 & & & \\
\hline
\end{tabular}

Elde edilen değerlerin ortalama ve standart sapma sonuçları Tablo 3'de gösterilmiştir. En yüksek vener porselen kırılma direnci değerlerinin (1690.80 N) alt yapısı anatomik şekilde hazırlanan chamfer basamaklı White Peaks kuronlarda, en düşük kırılma direnci değerlerinin $(690.00 \mathrm{~N})$ ise alt yapısı düz şekilde hazırlanan chamfer basamaklı Lava kuronlarda olduğu görülmüştür. Kenar bitim şekli açısından; shoulder basamaklı olarak hazırlanan kuronlardaki vener porselenlerinin kırılma direnci değerlerinin $(1245.23 \mathrm{~N})$, chamfer basamaklı olarak hazırlanan kuronlardaki vener porselenlerinin kırılma direnci değerlerinden daha düşük olduğu $(1310.40 \mathrm{~N})$ saptanmıştır. Alt yapı şekline göre; anatomik şekilde hazırlanan alt yapılar üzerindeki vener porselenlerinin kırılma direnci değerlerinin $(1333.50 \mathrm{~N})$, düz şekilde hazırlanan alt yapılardaki vener porselenlerinin kırılma direnci değerlerinden (1222.13 N) daha yüksek olduğu görülmüştür. Alt yapı materyallerine göre değerlendirildiğinde; en yüksek (1538.80 N) kırılma direnci değerleri White Peaks ile hazırlanan kuronlarda saptanmıştır. Bu grubu Zirkonzahn ile hazırlanan kuronlar $(1426.60 \mathrm{~N})$ izlemiştir. En düşük kırılma direnci değerleri $(868.05 \mathrm{~N})$ ise Lava alt yapı ile hazırlanan 
kuronlardaki vener porselenlerinde tespit edilmiştir (Tablo 3).

Tablo 3. Kırılma Direnç Değerlerinin Ortalama ve Standart Sapma Sonuçları $(\mathrm{N}=5)$

\begin{tabular}{|c|c|c|c|c|}
\hline Materyal & $\begin{array}{l}\text { Alt Yapı } \\
\text { Şekli }\end{array}$ & $\begin{array}{l}\text { Kenar Bitim } \\
\text { Şekli }\end{array}$ & $\begin{array}{l}\text { Ortalama } \\
\text { (N) }\end{array}$ & $\begin{array}{l}\text { Standart } \\
\text { Sapma }\end{array}$ \\
\hline \multirow{9}{*}{ Zirkonzahn } & \multirow{3}{*}{ Anatomik } & Soulder & 1383.00 & 35.43 \\
\hline & & Chamfer & 1408.40 & 78.17 \\
\hline & & Toplam & 1395.70 & 58.76 \\
\hline & \multirow{3}{*}{$\begin{array}{l}\text { Anatomik } \\
\text { Olmayan }\end{array}$} & Shoulder & 1475.60 & 33.61 \\
\hline & & Chamfer & 1439.40 & 53.02 \\
\hline & & Toplam & 1457.50 & 45.99 \\
\hline & \multirow{3}{*}{ Toplam } & Shoulder & 1429.30 & 58.67 \\
\hline & & Chamfer & 1423.90 & 65.06 \\
\hline & & Toplam & 1426.60 & 60.36 \\
\hline \multirow{9}{*}{ ava } & \multirow{3}{*}{ Anatomik } & Shoulder & 1016.40 & 82.31 \\
\hline & & Chamfer & 1070.00 & 132.61 \\
\hline & & Toplam & 1043.20 & 107.82 \\
\hline & \multirow{3}{*}{$\begin{array}{l}\text { Anatomik } \\
\text { Olmayan }\end{array}$} & Shoulder & 695.80 & 105.36 \\
\hline & & Chamfer & 690.00 & 113.14 \\
\hline & & Toplam & 692.90 & 103.11 \\
\hline & \multirow{3}{*}{ Toplam } & Shoulder & 856.10 & 191.04 \\
\hline & & Chamfer & 880.00 & 231.55 \\
\hline & & Toplam & 868.05 & 206.97 \\
\hline \multirow{9}{*}{$\begin{array}{l}\text { White } \\
\text { Peaks }\end{array}$} & \multirow{3}{*}{ Anatomik } & Shoulder & 1432.40 & 81.07 \\
\hline & & Chamfer & 1690.80 & 24.36 \\
\hline & & Toplam & 1561.60 & 147.42 \\
\hline & \multirow{3}{*}{$\begin{array}{l}\text { Anatomik } \\
\text { Olmayan }\end{array}$} & Shoulder & 1468.20 & 158.87 \\
\hline & & Chamfer & 1563.80 & 117.55 \\
\hline & & Toplam & 1516.00 & 141.06 \\
\hline & \multirow{3}{*}{ Toplam } & Shoulder & 1450.30 & 120.40 \\
\hline & & Chamfer & 1627.30 & 104.33 \\
\hline & & Toplam & 1538.80 & 142.36 \\
\hline \multirow{9}{*}{ Toplam } & \multirow{3}{*}{ Anatomik } & Shoulder & 1277.27 & 202.64 \\
\hline & & Chamfer & 1389.73 & 275.58 \\
\hline & & Toplam & 1333.50 & 244.46 \\
\hline & \multirow{3}{*}{$\begin{array}{l}\text { Anatomik } \\
\text { Olmayan }\end{array}$} & Shoulder & 1213.20 & 392.59 \\
\hline & & Chamfer & 1231.07 & 409.88 \\
\hline & & Toplam & 1222.13 & 394.46 \\
\hline & \multirow{3}{*}{ Toplam } & Shoulder & 1245.23 & 308.69 \\
\hline & & Chamfer & 1310.40 & 352.53 \\
\hline & & Toplam & 1277.82 & 330.16 \\
\hline
\end{tabular}

Alt yapı materyalleri arasındaki farklılıkları tespit etmek amacıyla yapılan Tukey HSD çoklu karşılaştırma testi sonuçlarına göre; vener porselenlerinin kırıma direnç değerleri arasında elde edilen farkların tüm gruplarda anlamlı ( $p<0.001)$ olduğu istatistiksel olarak saptanmıştır (Tablo 4).

Yapılan t-testi sonuçlarına göre; farklı kenar bitim $(p<0.05)$ ve alt yapı şekillerinde $(p<0.001)$ elde edilen değerler arasındaki farkların anlamlı olduğu istatistiksel olarak tespit edilmiştir.

Tablo 4. Materyallerin Kırılma Direnç Değerlerinin Tukey HSD Testi Sonuçlar

\begin{tabular}{lcccr}
\hline & & \multicolumn{3}{c}{ Örnek } \\
\cline { 4 - 5 } Materyal & $\mathrm{N}$ & 1 & 2 & 3 \\
\hline Lava & 20 & 868.05 & & \\
\hline Zirkonzahn & 20 & & 1426.60 \\
\hline White Peaks & 20 & & & 1538.80 \\
\hline Fark & & 1.000 & 1.000 & 1.000 \\
\hline
\end{tabular}

\section{Kopma Şekillerinin Değerlendirilmesi}

Vener porseleni ile zirkonyum alt yapı arasında meydana gelen adeziv kopma (\%55) ve her iki kırılma tipinin de gözlenmesiyle oluşan kombine (adeziv + koheziv) kopma (\%45) şekilleri görülmüş olup, hiç bir örnekte tamamen koheziv kopma şekline rastlanmamıştır. Zirkonzahn alt yapılı kuronlarda \%50 oranında adeziv kopma şekli, \%50 oranında kombine kopma, Lava alt yapılı kuronlarda, \%60 oranında adeziv kopma, \%40 oranında kombine kopma şekli, White Peaks alt yapılı kuronlarda ise \%55 oranında adeziv kopma, \%45 oranında kombine kopma şekli tespit edilmiştir (Tablo 5).

Tablo 5. Vener Porselenlerinin Kopma Şekillerinin Dağııımı

\begin{tabular}{|c|c|c|c|}
\hline \multirow[b]{2}{*}{$\begin{array}{l}\text { Alt Yapı } \\
\text { Materyali }\end{array}$} & \multirow[b]{2}{*}{$\begin{array}{c}\text { Alt Yapı ve } \\
\text { Kenar Bitim Şekli }\end{array}$} & \multicolumn{2}{|r|}{ Kopma Şekli } \\
\hline & & Adeziv & $\begin{array}{c}\text { Kombine } \\
\text { (Adeziv + } \\
\text { Koheziv) }\end{array}$ \\
\hline \multirow{5}{*}{ Zirkonzahn } & Anatomik Shoulder & 0 & 5 \\
\hline & Anatomik Chamfer & 2 & 3 \\
\hline & $\begin{array}{l}\text { Anatomik Olmayan } \\
\text { Shoulder }\end{array}$ & 4 & 1 \\
\hline & $\begin{array}{c}\text { Anatomik Olmayan } \\
\text { Chamfer }\end{array}$ & 4 & 1 \\
\hline & Toplam & $10(\% 50)$ & $10 \% 50)$ \\
\hline \multirow{5}{*}{ Lava } & Anatomik Shoulder & 2 & 3 \\
\hline & Anatomik Chamfer & 1 & 4 \\
\hline & $\begin{array}{c}\text { Anatomik Olmayan } \\
\text { Shoulder }\end{array}$ & 4 & 1 \\
\hline & $\begin{array}{c}\text { Anatomik Olmayan } \\
\text { Chamfer }\end{array}$ & 5 & 0 \\
\hline & Toplam & $12(\% 60)$ & $8(\% 40)$ \\
\hline \multirow{5}{*}{$\begin{array}{l}\text { White } \\
\text { Peaks }\end{array}$} & Anatomik Shoulder & 2 & 3 \\
\hline & Anatomik Chamfer & 0 & 5 \\
\hline & $\begin{array}{l}\text { Anatomik Olmayan } \\
\text { Shoulder }\end{array}$ & 5 & 0 \\
\hline & $\begin{array}{c}\text { Anatomik Olmayan } \\
\text { Chamfer }\end{array}$ & 4 & 1 \\
\hline & Toplam & $11 \% 55)$ & $9(\% 45)$ \\
\hline Toplam & $\mathrm{N}=60$ & $33 \% 55)$ & $27(\% 45)$ \\
\hline
\end{tabular}




\section{TARTIŞMA}

Seramikler ile alt yapı materyallerinin ilk kullanıldıkları günden günümüze kadar içeriklerinde ve fiziksel özelliklerinde gelişmeler kaydedilmiş olmasına karşın, oklüzal kuvvetler, yorulma, travma, mikro defektler veya uygun olmayan tasarım gibi sebeplerle restorasyonlarda, ağız içinde kırılmalar oluştuğu

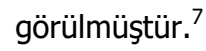

Tam seramik restorasyonlarda porselenlerin alt yapıdan ayrılması en sık görülen klinik başarısızlık lardan biridir. $^{8}$ Zirkonyum alt yapılı destekli restorasyonların 5 yıllık takibi sonunda \%95.9-98.5 klinik olarak kullanım süresine sahipken, $10 \mathrm{yıl}$ takip sonunda bu oran $\% 67.2$ düşmektedir. ${ }^{1,9}$

Tam seramik alt yapılarda günümüzde kullanılan CAD-CAM sistemlerinde, beyaz aşama yarı sinterlenmiş (unHIPped) veya yeşil aşama tam sinterlenmiş (HIPped) zirkonyum blok kullanılmaktadır. Yarı sinterlenmiş zirkonyum bloklardan elde edilen alt yapılara sinterleme işlemi uygulanmaktadır. $\mathrm{Bu}$ işlem sonunda zirkonyum yapılar boyutsal olarak \%20-25 büzülme göstermektedir. ${ }^{10}$ Yarı sinterlenmiş zirkonyum blokların aksine tam sinterlenmiş zirkonyum bloklara sinterleme işlemi uygulanmamakta ve boyutsal olarak büzülme görülmemektedir. ${ }^{11}$ Bu çalışmada diş hekimliğinde kullanılan farklı tipteki zirkonyum bloklar ve bu bloklar kullanılarak üretim yapılan üç farklı sistem karşılaştırılmıştır.

Alt yapılar üzerine hazırlanan vener porselenlerinin kalınlıkları mevcut oklüzal boşluğa, restorasyonların anatomik karakterizasyon boyutuna bağlı olarak değişiklik göstermektedir. İdeal porselen kalınlığının 1-1.5 mm arasında olması gerektiği ifade edilmiştir. ${ }^{12} \mathrm{Bu}$ çalışmada vener porselenlerinin hazırlanması sırasında standardizasyonun sağlanabilmesi için silikon kalıplar kullanılmıştır. ${ }^{13}$

Diş kesimi sırasında oluşturulan basamak, çiğneme kuvvetlerinin diş üzerinde dengeli şekilde dağılmasını sağlarken kuronun statik gücünü artırmaktadır. ${ }^{14}$ Diş preparasyonu sırasında uygulanan basamak şekli gerilimin dağılımında önemli rol oynamaktadır. ${ }^{15}$ Shoulder basamak şekli oklüzal kuvvetlere direnci artırmakta ve porselende kırıklara neden olabilecek stresleri minimalize etmekte, sağlıklı restorasyon konturları ve maksimum estetik için alan oluşturmaktadır. ${ }^{16}$ Aynı şekilde chamfer kenar bitim şekli ile de yeterli kenar kalınlığında ve sağlamlıkta restorasyonlar hazırlanabilmektedir. ${ }^{17,18}$
Beuer ve ark. ${ }^{19}$ derin chamfer, chamfer ve shoulder basamak tipleri ile hazırlanan tam seramik restorasyonların kırılma dirençlerini incelemişler, shoulder basamaklı örneklerin daha fazla kırılma direnci değerleri gösterdiğini belirtmişlerdir. Di Iorio ve ark. ${ }^{20}$ Procera tam seramik kuronların $50^{\circ}$ chamfer ve $90^{\circ}$ shoulder basamakta kırılma dirençlerini değerlendirmişlerdir. Araştırma sonucunda Procera tam seramik restorasyonlarda basamak şekli farklılığının kırılma direncini etkilediği ve shoulder basamak ile hazırlanan örneklerin kırılma dayanıklılı̆ının chamfer basamak ile hazırlananlardan daha fazla olduğu tespit edilmiştir. Cho ve ark. ${ }^{21} 0.9 \mathrm{~mm}$ ve $1.2 \mathrm{~mm}$ genişliğinde chamfer şeklinde oluşturulan basamaklarla hazırlanan tam seramik restorasyonların, 1.2 shoulder ve 1.2 rounded end shoulder basamak tipleriyle hazırlananlardan daha fazla kırılma direnci gösterdiğini ifade etmişlerdir. Jalalian ve ark. $^{22}$ çalışmaları sonucunda, chamfer basamak ile hazırlanan zirkonyum alt yapılı örneklerin kırılma dirençlerinin, shoulder basamak ile hazırlanan zirkonyum alt yapılı örneklerden daha fazla olduğunu istatistiksel olarak saptamışlardır. Miura ve ark. ${ }^{23}$ shoulder, rounded shoulder ve derin chamfer basamak tiplerini Sonlu Elemanlar Stres Analiz yöntemi ile karşılaştırmışlar, derin chamfer ve rounded shoulder basamak tipinin zirkonyum restorasyonların mekanik performanslarını geliştirdiğini gözlemlemişlerdir. Malament ve Socransky ${ }^{24}$ shoulder ve chamfer basamak şekillerinin tam seramiklerde vener porselenlerin kırılma riski açısından önemli bir fark oluşturmadığını belirtmişlerdir.

Tam seramik restorasyonlarda uygulanan basamak şekillerinin vener porselenlerinin kırılma direnci üzerindeki etkisi ile ilgili fikir birliğinin olmadığı görülmektedir. Bu çalışma sonucunda elde edilen veriler genel olarak değerlendirildiğinde; chamfer basamaklı olarak hazırlanan kuronlardaki vener porselenlerinin kırılma direnç değerlerinin (1310.40 N), shoulder basamak ile hazırlananlardan (1245.23 N) daha fazla olduğu görülmüştür.

Alt yapıların modifikasyonu teknik komplikasyonların azalmasını sağlayan en önemli faktörlerdendir. Yapılan çalışmalarda anatomik kesim yapılan dişler üzerinde hazırlanan seramik alt yapılara uygulanan vener porselenlerinin, düz (anatomik olmayan) kesim yapılan dişlerde hazırlanan restorasyonlardan daha fazla kırılma direncine sahip oldukları görülmüştür. ${ }^{25,26}$

Kullanıma sunulduğu ilk yıllarda genellikle 
prepare edilmiş dişler üzerinde düz şekilde hazırlanan 3Y-TZP alt yapılara porselen ilave edilerek restorasyonlar tamamlanmış, bu şekilde hazırlanan restorasyonların tüberkül tepelerinde porselen kalınlığında artış meydana gelmiştir. Bu durum anatomik alt yapılarla desteklenmeyen vener porselen tabakaları arasında stres dağılımını etkilemekte ve oklüzal-lateral kuvvetler porselen yapısında kırılma ve çatlama oluşturmaktadır. ${ }^{27}$ Alt yapıların anatomik şekilde hazırlanması porselen kalınlıklarının eşit olmasını, oklüzal ve lateral kuvvetlere karşı porselenlerin desteklenmesini sağlamaktadır. ${ }^{28}$

Sundh ve Sjogren ${ }^{13}$ yaptıkları çalışmada tam sinterlenmiş bloklardan anatomik ve anatomik olmayan şekilde hazırladıkları zirkonyum alt yapılara uyguladıkları iki farklı porselen materyalinin kırıma dirençlerini değerlendirmişlerdir. Çalışma sonucunda anatomik olarak şekillendirilen zirkonyum alt yapılardaki vener porselenlerinin kırılma dirençlerinin anatomik olmayan zirkonyum alt yapılardakinden istatistiksel olarak anlamlı derecede yüksek olduğunu, kullanılan porselen materyalleri arasında ise anlamlı bir farklılık olmadığını istatistiksel olarak saptamışlardır.

Larsson ve ark. ${ }^{29}$ yarı sinterlenmiş ve tam sinterlenmiş zirkonyum bloklardan hazırladıkları anatomik ve anatomik olmayan alt yapılar üzerine uyguladıkları farklı seramik materyallerinin kırıma dirençlerini incelemişlerdir. Yarı ve tam sinterlenmiş alt yapılar ve farklı porselen materyallerinin kırılma dirençleri arasındaki farkların anlamlı olmadığını, bununla birlikte anatomik olarak hazırlanan zirkonyum alt yapıların kırılma dirençlerinin anatomik olmayan zirkonyum alt yapıların kırılma dirençlerinden yüksek olduğunu istatistiksel olarak tespit etmişlerdir. Anatomik olmayan zirkonyum alt yapılara uygulanan porselenlerdeki kırımanın daha büyük boyutta olduğunu belirtmişlerdir.

Bonfante ve ark. ${ }^{30}$ anatomik kuron şeklinde ve anatomik olmayan şekilde tasarlanan alt yapıları Sonlu Elemanlar Stres Analiz yöntemi ile karşılaştırmışlar, anatomik alt yapıların daha yüksek stres dayanımı gösterdiğini belirtmişlerdir.

Bu çalışmada en yüksek vener porselen kırılma direnci değerlerinin $(1690.80 \mathrm{~N}$ ) alt yapısı anatomik şekilde hazırlanan chamfer basamaklı White Peaks kuronlarda, en düşük kırılma direnci değerlerinin (690.00 $\mathrm{N}$ ) ise alt yapısı düz şekilde hazırlanan chamfer basamaklı Lava kuronlarda olduğu görülmüştür. Alt yapısı anatomik şekilde hazırlanan kuronlarda vener porselenlerinin kırılma direnç değerlerinin fazla olmasının porselene yeterli destek sağlanmasına bağlı olduğunu düşünmekteyiz.

Sundh ve Sjogren ${ }^{31}$ yarı sinterlenmiş ve tam sinterlenmiş zirkonyum bloklardan hazırladıkları alt yapılara vener porseleni uyguladıktan sonra kırılma dirençlerini değerlendirmişlerdir. Yarı sinterlenmiş zirkonyum-porselen örneklerin kırılma dirençlerinin, tam sinterlenmiş zirkonyum-porselen örneklerin kırılma dirençlerinden daha fazla olduğunu saptamışlardır. Bu sonucun, yarı sinterlenmiş zirkonyum alt yapılara uygulanan porselenlerin zirkonyum yüzeyindeki çatlaklara infiltre olmasına ve ısıl işlemle birlikte kırıma direncinin artmasına bağlı olarak oluştuğunu ifade etmişlerdir.

$\mathrm{Bu}$ çalışmada tam sinterize zirkonyum alt yapılar üzerinde hazırlanan vener porselenlerinin kırılma direnci değerlerinin (1538.80 N), yarı sinterize (868.05 $\mathrm{N})$ ve manuel $(1426.60 \mathrm{~N})$ yöntemle hazırlanan alt yapılardaki vener porselenlerinden daha fazla olduğu

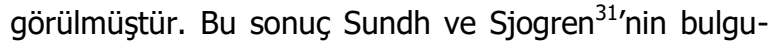
ları ile uyum göstermemektedir. Araştırmada yarı sinterlenmiş bloklardan alt yapılar üretildikten sonra sinterizasyon işlemine tabi tutulmuş, yeterli sertlikte ve düzgün yüzeyde alt yapılar hazırlanmıştır. Bu nedenle Sundh ve Sjogren ${ }^{31}$ 'nin belirttiği gibi boşluklara vener porseleninin girdiğini düşünmemekteyiz.

Bu çalışmada, Zirkonzahn alt yapılı kuronlarda \%50 oranında adeziv kopma, \%50 oranında kombine kopma, Lava alt yapılı kuronlarda, \%60 oranında adeziv kopma, \%40 oranında kombine kopma, White Peaks alt yapılı kuronlarda ise \%55 oranında adeziv kopma, \%45 oranında kombine kopma şekli tespit edilmiştir. Kırılma direncinin fazla olduğu anatomik alt yapılar üzerinde hazırlanan bazı kuronlarda vener porseleni ile birlikte alt yapı seramiğinin ve epoksi güdük materyalinin kırıldığı gözlemlenmiştir.

Ağızda kullanım sırasında görülen porselen ufalanmaları, materyale veya alt yapı porseleninin kalınlık oranı ve alt yapı şekli gibi protez dizaynlarına, ${ }^{25}$ sağlam bir alt yapı üzerindeki vener porseleninde koheziv ufalanmaların olması aşırı yük uygulanmasına, tabakalar şeklindeki kopmalar ise zayıf vener bağlantısına ve ara yüzeydeki lokalize gerilme streslerine bağlı olabilir. Zirkonyum alt yapıların kullanıldığı tabakalı restorasyonlarda alt yapı-vener ara yüzünde oluşan gerilme stresleri, iki materyal arasındaki termal genleşme katsayısı farklılığına bağlı olarak oluşmaktadır. ${ }^{32}$ 
Bu çalışmada ağız ortamındaki ısısal değişiklikler vb. gibi faktörlerin vener porselenlerinin kırılma direnci değerlendirilirken yansıtılamaması çalışmanın sınırlamalarını oluşturmaktadır.

\section{SONUÇ} edilmiştir:

$\mathrm{Bu}$ in vitro çalışmada aşağıdaki sonuçlar elde

1. En yüksek vener porselen kırılma direnci değerlerinin alt yapısı anatomik şekilde hazırlanan chamfer basamaklı White Peaks kuronlarda, en düşük kırılma direnci değerlerinin ise alt yapısı düz şekilde hazırlanan chamfer basamaklı Lava kuronlarda olduğu görülmüştür.

2. Shoulder basamaklı olarak hazırlanan kuronlardaki vener porselenlerinin kırılma direnci değerlerinin, chamfer basamaklı olarak hazırlanan kuronlardaki vener porselen kırılma direnci değerlerinden daha düşük olduğu saptanmıştır.

3. Anatomik şekilde hazırlanan alt yapılar üzerindeki vener porselenlerinin kırıma direncinin düz şekilde hazırlanan alt yapılardaki vener porselenlerinin kırılma direncinden daha fazla olduğu tespit edilmiştir.

4. En yüksek vener porselen kırılma direnci değerleri White Peaks alt yapılar üzerinde hazırlanan kuronlardaki vener porselenlerinde, en düşük kırılma direnci değerleri ise Lava alt yapı ile hazırlanan kuronlardaki vener porselenlerinde belirlenmiştir.

Murat Alkurt: ORCID ID: 0000-0001-9324-0158 Zeynep Yeşil Duymuş: ORCID ID: 0000-0001-7162-8792

\section{KAYNAKLAR}

1. Mıura S, Kasahara S, Yamauchı S, Okuyama Y, Izumıda A, Aıda J, Egusa H. Clinical Evaluation of zirconia-basedall-ceramic single crowns: an up to 12-year retrospectivecohort study. Clin Oral Invest 2018; https://doi.org/10.1007/s00784-017-2142-y.

2. Tinschert J, Zwez D, Marx R, Anusavice KJ. Structural reliability of alumina-, feldspar-leucitemica-and zirconia-based ceramics. J Dent 2000; 28: 529-35.

3. Oılo M, Gjerdet NR. Fractographic analyses of allceramiccrowns: a study of 27 clinically fractured crowns. Dent Mater 2013; 29: e78-84.

4. Dogan S, Raıgrodskı AJ, Zhang $H$, Mancl LA. Prospectivecohort clinical study assessing the 5- year survival and successof anterior maxillary zirconia-based crowns with customizedzirconia copings. J Prosthet Dent 2017; 117: 226-32.

5. Omori S, Komada W, Yoshida K, Miura H. Effect of thickness of zirconia-ceramic crown frameworks on strength and fracture pattern. Dent Mater J 2013; 32: 189-94.

6. Rafferty BT, Janal MN, Zavanellı RA, Sılva NR, Rekow ED, Thompson VP, Coelho PG. Design features of a three-dimensional molar crown and related maximum principalstress. A finite element model study. Dent Mater 2010; 26: 156-63.

7. Llobell A, Nicholls JI, Kois JC, Daly CH. Fatigue life of porcelain repair systems. Int J Prosthodont 1992; 5: 205-13.

8. Pjetursson BE, Tan WC, Tan K, Bragger U, Zwahlen M, Lang NP. A systematic review of the survival and complication rates of resin-bonded bridges after an observation period of at least 5 years. Clin Oral İmplants Res 2008; 19: 131-41.

9. Nejatıdanesh F, Moradpoor $H$, Savabı O. Clinical outcomesof zirconia-based implant- and toothsupported single crowns. Clin Oral Investig 2016; 20: $169-78$.

10. Piwowarczyk A, Ottl P, Lauer HC, Kuretzky T. A clinical report and overview of scientific studies and clinical procedures conducted on the 3M ESPE Lava all-ceramic system. J Prosthodont 2005; 14 : 39-45.

11. Besimo CE, Spielmann HP, Rohne, HP. Computedassisted generation of all-ceramic crowns and fixed partial dentures. Int. J Comput Dent 2001; 4: 243-62.

12. Lawn BR, Pajares A, Zhang Y, Deng Y, Polack MA, Lloyd IK, Rekow ED, Thompson VP. Materials design in the performance of all-ceramic crowns. Biomaterials 2004; 25: 2885-92.

13. Sundh A, Sjogren G. A comparison of fracture strength of yttrium-oxide- partially-stabilized zirconia ceramic crowns with varying core thickness, shapes and veneer ceramics. J Oral Rehabil 2004; 31: 682-8.

14. Goodacre CJ, Campagni WV, Aquilino SA. Tooth preparations for complete crowns: an art form based on scientific principles. J Prosthet Dent 2001; 85: 363-76.

15. Güngör $M A$, Dündar $M$, Karaoğlu Ç, Sonugelen $M$, Artunç $C$. Tam seramik malzemelerde basamak

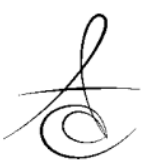


şeklinin gerilim dağılımına etkisi: Sonlu elemanlar stres analizi. Ege Üniv Diş Hek Fak Derg 2005; 26: 145-53.

16. Shillingburg $H$, Hobo $S$, Whitsett $L$, Jacobi $R$, Brackett S. Principles of tooth preparation. In: Fundamentals of fixed prosthodontics. 3 ed. Chicago; Quintessence Publishing: 1997. p. 119137.

17. Ernst $C P$, Cohnen U, Stender E, Willershausen B. In vitro retentive strength of zirconium oxide ceramic crowns using different luting agents. J Prosthet Dent 2005; 93: 551-8.

18. Alkurt $M$, Yesil Duymus Z. Değişik yöntemlerle hazırlanan metal alt yapılar üzerindeki veneer porselenlerinin kırılma direncine farklı kenar bitim şekillerinin etkisinin incelenmesi. Atatürk Üniv Diş Hek Fak Derg 2016; 26: 465-72.

19. Beuer F, Aggstaller H, Edelhoff D, Gernet W. Effect of preparation design on the fracture resistance of zirconia crown copings. Dent Mater J 2008; 27: 362-7.

20. Di Iorio D, Murmura G, Orsini G, Scarano A, Caputi S. Effect of margin design on the fracture resistance of Procera all ceram cores: an in vitro study. J Contemp Dent Pract 2008; 9: 1-8.

21. Cho L, Choi J, Yi YJ, Park CJ. Effect of finish line variants on marginal accuracy and fracture strength of ceramic optimized polymer/fiberreinforced composite crowns. J Prosthet Dent 2004; 91: 554-60.

22. Jalalian E, Atashkar B, Rostami R. The effect of preparation design on the fracture resistance of zirconia crown copings (computer associated design/computer associated machine, CAD/CAM system). J Dent (Tehran, Iran) 2011; 8: 123-9.

23. Miura S, Kasahara S, Yamauchi S, Egusa H. Effect of finish line design on stress distribution in bilayer and monolithic zirconia crowns: a threedimensional finite element analysis study. Eur J Oral Sci 2018; 126: 159-65.

24. Malament KA, Socransky SS. Survival of Dicor glass-ceramic dental restorations over 14 years. Part II: effect of thickness of Dicor material and design of tooth preparation. J Prosthet Dent 1999; 81: 662-7.
25. Guess PC, Bonfante EA, Silva NR, Coelho PG, Thompson VP. Effect of core design and veneering technique on damage and reliability of Y-TZPsupported crowns. Dent Mater 2013; 29: 307-16.

26. Yesil Duymus Z, Alkurt M. Değişik yöntemlerle hazırlanan metal alt yapılar üzerindeki veneer porselenlerinin kırılma direncine farklı alt yapı şekillerinin etkisinin incelenmesi. Atatürk Üniv Diş Hek Fak Derg 2016; 26: 457-64.

27. Ha SR, Kim SH, Han JS, Yoo SH, Jeong SC, Lee JB, Yeo IS. The influence of various core designs on stress distribution in the veneered zirconia crown: A finite element analysis study. J Adv Prosthodont 2013; 5: 187-97.

28. Benetti $P$, Pelogia $F$, Valandro LF, Bottino MA, Bona $A D$. The effect of porcelain thickness and surface liner application on the fracture behavior of a ceramic system. Dent Mater 2011; 27: 948-53.

29. Larsson C, El Madhoun S, Wennerberg A, Vult von Steyern $\mathrm{P}$. Fracture strength of yttria-stabilized tetragonal zirconia polycrystals crowns with different design: an in vitro study. Clin Oral İmplants Res 2012; 23: 820-6.

30. Bonfante EA, Rafferty B, Zavanelli RA, Silva NR, Rekow ED, Thompson VP, Coelho PG. Thermal/mechanical simulation and laboratory fatigue testing of an alternative yttria tetragonal zirconia polycrystal core-veneer all-ceramic layered crown design. Eur J Oral Sci 2010; 118: 202-29.

31. Sundh A, Sjogren G. Fracture resistance of allceramic zirconia bridges with differing phase stabilizers and quality of sintering. Dent Mater 2006; 22: 778-84.

32. Aboushelib MN, Feilzer AJ, Kleverlaan CJ. Bridging the gap between clinical failure and laboratory fracture strength tests using a fractographic approach. Dent Mater 2009; 25: 383-91.

\author{
Yazışma Adresi \\ Dr. Öğr. Üyesi Murat ALKURT \\ Recep Tayyip Erdoğan Üniversitesi \\ Diş Hekimliği Fakültesi \\ Protetik Diş Tedavisi Anabilim Dalı, Rize \\ E-Mail: muratalkurt@hotmail.com
}

